\title{
Numerical Analysis of Natural Smoke Ventilation Design System under External Wind Effect in Factory Compartment
}

\author{
Chen-Wei Chiu ${ }^{1}$, Yi-Hong Chang ${ }^{2}$ and Yi-Liang Shu ${ }^{3}$ \\ 1. Department of Fire Safety, National Taiwan Police College, Taipei 11696, Taiwan, R.O.C. \\ 2. Department of Safety, Health, and Environmental Engineering, National Yunlin University of Science and Technology, Yunlin \\ 64002, Taiwan, R.O.C. \\ 3. Department of Safety Health and Environmental Engineering, Central Taiwan University of Sciences and Technology, Taichung \\ 40601, Taiwan, R.O.C.
}

\begin{abstract}
This study applied the numerical simulator tool FDS (fire dynamics simulator), Version 5.53, and focused on the simulation of the natural smoke flow ventilation design system, an innovative ventilation design using the parallel processing technology MPI (message passing interface). The design was then compared with the exhaust efficiency of a typical natural smoke vent. The natural smoke flow ventilation design system was located at the top of the factory, where smoke streams effectively converged. Therefore, the source of fire was designed to be $2 \mathrm{MW}$, which has a better exhaust efficiency than typical natural smoke vent with same area. The simulation discovered that the exhaust efficiency of the natural smoke ventilation design systems is higher than that of typical natural smoke vent with 2 times the opening area and that was not affected by external wind speed. Instead, external wind speed can help to enhance the exhaust efficiency. Smoke exhaust of typical natural smoke vents was affected by external wind speed, even leading them to become air inlets which would disturb the flow of air indoors, leading to smoke accumulation within the factory.
\end{abstract}

Key words: FDS, MPI, natural smoke flow ventilation design system, wind effect.

\section{Introduction}

This study focused on the simulation of natural self-made smoke ventilation design system, an innovative ventilation design, and compared its efficiency with a typical natural smoke vent, including the comparison of smoke exhaustion under external wind speed and non-external wind speed conditions. The objective was to rectify the weaknesses of existing natural smoke vent, applying them in industrial and technological plants and placing them at the top of the plant. Taking consumer safety and economic factors into account, smoke decompression and management technologies were used in the natural smoke ventilation design system. The exhaust

Corresponding author: Chen-Wei Chiu, Ph.D., associate professor, research field: fire protection engineering. E-mail: eswin.wei@gmail.com. efficiency of the natural smoke ventilation design system was tested by evaluating the influencing parameters, such as smoke volume, wind speed and wind direction.

Seldom consideration is given on how the natural wind of outside the building affects the smoke migration pattern. However, it will be unrealistic to ignore the natural wind factor in smoke control design. Wind effects play an important role in building ventilation, which were investigated on performance of static smoke exhaust systems (horizontal ceiling vents) and modified the key equations on calculating the smoke exhaust rates and the required vent area [1]. More researches about wind effects on smoke exhaust systems under different fire scenarios are needed to promote the safety of high-rise buildings. Furthermore, research about wind effects on 
compartment fire in high-rise buildings is also needed to provide guidelines for fire safety design. Porch and Trebukov [2] had analyzed wind effects on the motion of buoyant smoke motion and control in a compartment. In the field of ventilation, natural ventilation of buildings generated by temperature differences and by the wind receives much more attention and multiple steady state behavior was found in recent years [3-5].

To analyze how the natural wind can impact on the fire and smoke generated in the atrium of a large space building, the PHOENICS, which is the general purpose CFD (computational fluid dynamics) software with the statistical data about the natural wind from the specific area/city, can provide some references for the future smoke control designs [6]. Various wind effects were discussed [7-9] to analyze the movement and concentration of the smoke within a building, which is also affected by ambient winds that generate a non-uniform pressure distribution on its outer envelope. A general analysis of wind effects on the motion of buoyant smoke motion and control in buildings is presented [10]. It identifies the role of the significant parameters, defines a dimensionless threshold wind speed, at which wind effects become significant, and shows that probability of significant wind effects is not small. A series of unsteady atria fire calculations are performed using a finite-volume CFD program on two and three dimensional generic buildings immersed in simulated atmospheric boundary layers. The model results reveal that external winds can modify the infiltration and exfiltration of air through external doors and windows, distort thermal and smoke columns rising above test fires in the atria [11].

\section{Natural Smoke Flow Ventilation Design System and Scenario Analysis}

\subsection{Natural Smoke Flow Ventilation Design System}

The simulation scope of this study is shown in Fig. 1, with the length in the $\mathrm{X}$-direction ranging from $3 \mathrm{~m}$ to $20 \mathrm{~m}$, the length in the $\mathrm{Y}$-direction ranging from 0 to
$20 \mathrm{~m}$ and the length in the $\mathrm{Z}$-direction ranging from 0 to $18 \mathrm{~m}$. The length in the X-direction for the factory floor ranged from 0 to $16 \mathrm{~m}$, whereas the length in the Y-direction ranged 0 to $20 \mathrm{~m}$. Therefore, the floor area of the factory was $320 \mathrm{~m}^{2}$, with the highest point of the roof at $14.4 \mathrm{~m}$. That was also a $2 \mathrm{~m}$ wide and $2 \mathrm{~m}$ tall opening to allow for the automatic replenishment of gas. The simulated heat release rate was decided based upon the heat release rate on the NIST (National Institute of Standards and Technology) website. The heat release rate for using diesel as fuel was $2 \mathrm{MW}$, with an extremely rapid rate of combustion. This study used a particular processing venue with an actual combustion area of $4 \mathrm{~m}^{2}(2 \mathrm{~m} \times 2 \mathrm{~m})$. In addition, the simulated timing to determine whether or not workers would be safe was set at $200 \mathrm{~s}$, given a scenario in which it would take approximately $10 \sim 20 \mathrm{~s}$ of evacuation time for a walking distance of $20 \mathrm{~m}$ from a standalone factory.

The Auto-CAD (computer-aided design) real image of natural smoke flow ventilation design system is shown in Fig. 2. Fig. 3 shows the real image of the natural smoke ventilation system structure. According to Fig. 3, it is clear that not only could the natural smoke ventilation system prevent roof's rain water from permeating indoors, but also it could increase exhaust efficiency through its air flow circulation design.

\subsection{Grid Settings}

This study used the numerical simulation tool FDS

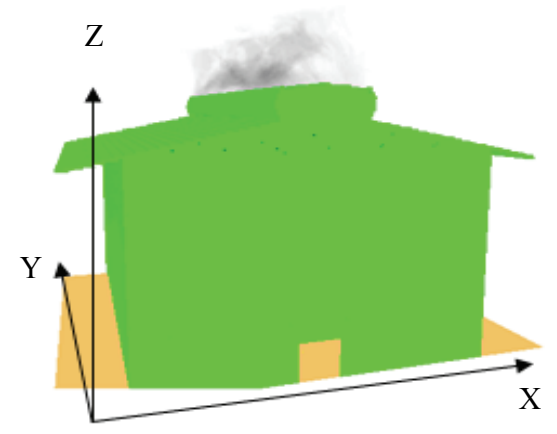

Fig. 1 Simulation scope. 


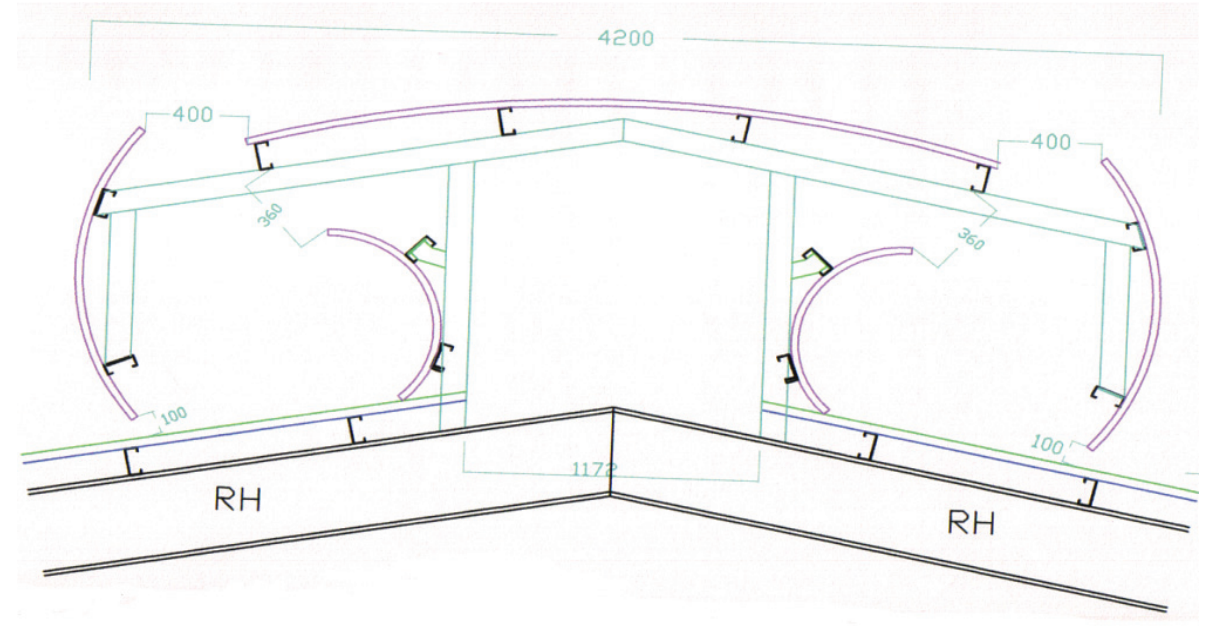

Fig. 2 AutoCAD diagram of natural smoke flow ventilation design system.
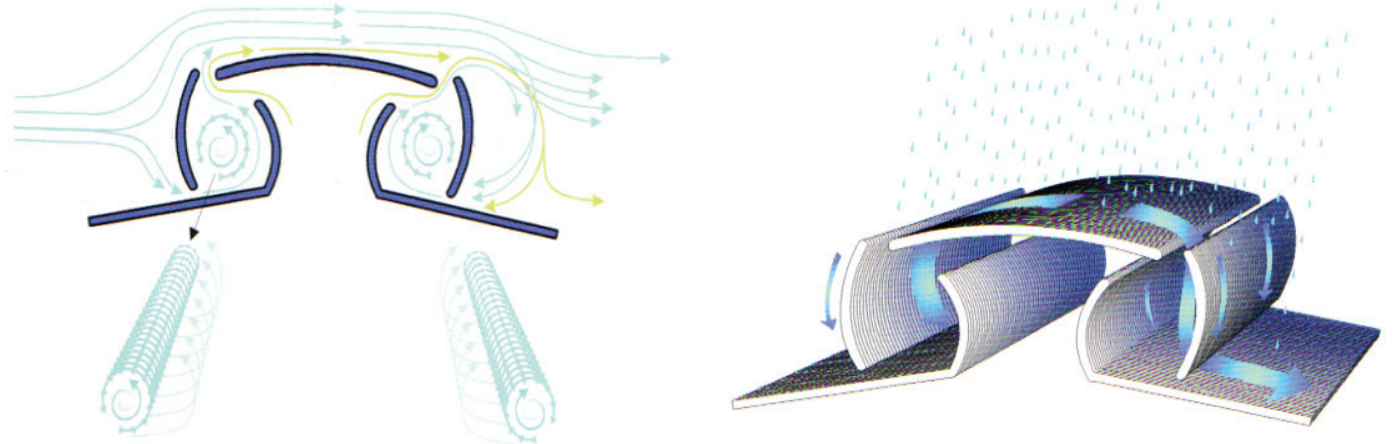

Fig. 3 Air and rain flow design of natural smoke flow ventilation system.
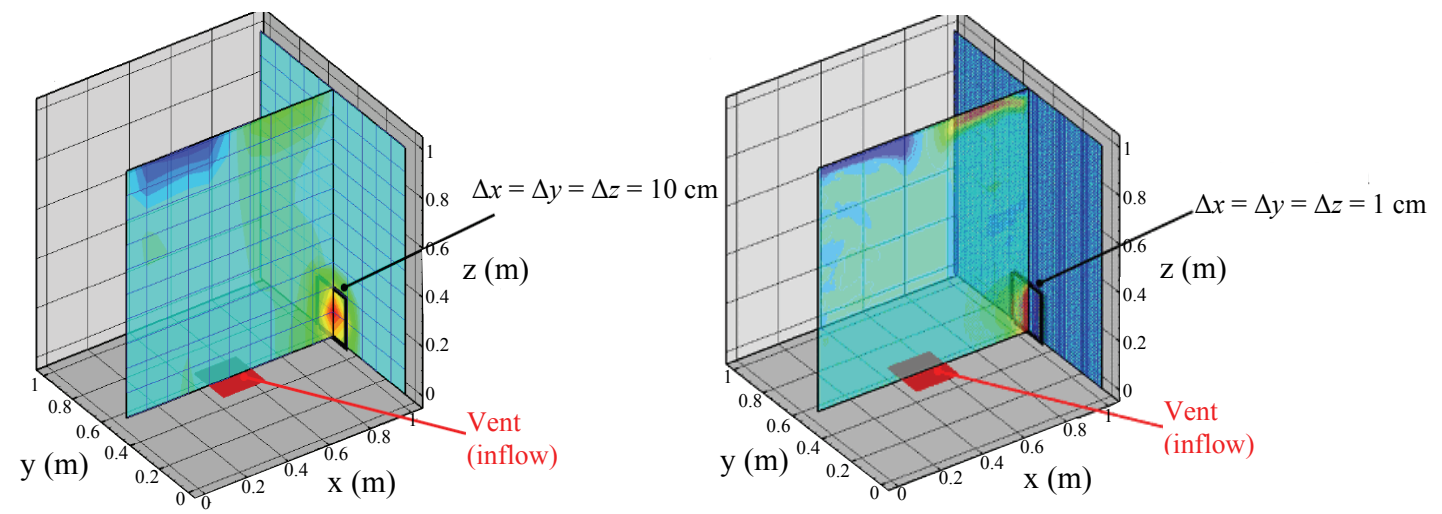

Fig. 4 Comparative analysis of different grid point errors.

(fire dynamics simulator) (Version 5.53) [12] to conduct simulations with MPI (message passing interface) technology using three computers. Due to numerical method requirements, the numerical model was constructed using a stacking method. To accurately simulate the structure of the natural smoke ventilation system, this study conducted grid simulation of $0.1 \mathrm{~m}(10 \mathrm{~cm})$ in size and grid point analysis of $1 \mathrm{~cm}$ (as shown in Fig. 4), which leads to an error value below $1 \%$. The natural exhaust vent used for comparison in this study was situated at the intersection between the roof and wall. As the vent for the natural smoke ventilation system is $0.36 \mathrm{~m}$, the natural exhaust vent was set to be $0.4 \mathrm{~m}$ in height and $20 \mathrm{~m}$ in length, with an area of $16 \mathrm{~m}^{2}$, in order to conduct comparisons. The floor area of the factory was 
$320 \mathrm{~m}^{2}$, and the area of the natural exhaust vent thus has to be a minimum of $0.02 \times 320=6.4 \mathrm{~m}^{2}$ according to fire safety regulations [13]. The natural exhaust vent used in this study had an area of $16 \mathrm{~m}^{2}$, far greater than required in the aforementioned regulations.

\subsection{Scenarios}

In comparing the natural smoke management design and typical natural smoke vent, this study focused on Table 1 and conducted numerical simulations, mainly external wind and non-external wind, on natural smoke flow ventilation design systems and typical natural smoke vents. This study used a wind speed of $2 \mathrm{~m} / \mathrm{s}$ and $8 \mathrm{~m} / \mathrm{s}$ with a wind direction of $\mathrm{X}^{-}$towards $\mathrm{X}+$. The connotations behind the wind speeds can be referred to in Table 2 (Beaufort wind scale). A wind speed of $2 \mathrm{~m} / \mathrm{s}$ implies light wind that can be felt by human beings, capable of shaking leaves and moving typical wind indicators; A wind speed of $8 \mathrm{~m} / \mathrm{s}$ implies a breeze which is capable of shaking small trees with leaves.

\subsection{Testing Point}

To conduct comparisons of smoke exhaust efficiency, this study recorded smoke concentration levels by setting up testing points in the numerical simulation model. It mainly recorded at the four red points shown in Fig. 5. There are three to four recording points, with each recording position set to record the soot density at the various heights of $1.8 \mathrm{~m}$, $3 \mathrm{~m}, 6 \mathrm{~m}, 9 \mathrm{~m}$ and $12 \mathrm{~m}$, respectively. Table 3 shows the FDS testing points.

\section{Results and Discussions}

\subsection{Natural Smoke Flow Ventilation Design System}

According to comparison of soot density for natural smoke ventilation design systems, Figs. 6-11 represent the soot density variation with time when recording soot density from 3-m height testing points (TC5, TC9, TC13 and TC16) for Scenarios 1 to 3 , respectively. It can be discovered from Figs. 6, 8 and 10 that the soot density at $3 \mathrm{~m}$ decreases with the increase in wind speed. In other words, the wind speed has a positive

Table 1 Simulation scenarios.

\begin{tabular}{ll}
\hline Serial number & Simulation contents \\
\hline 1 & Natural smoke flow ventilation design system, no wind \\
\hline 2 & Natural smoke flow ventilation design system, wind direction $\mathrm{X}$ - towards X+, $2 \mathrm{~m} / \mathrm{s}$ \\
\hline 3 & Natural smoke flow ventilation design system, wind direction $\mathrm{X}-$ towards X+, $8 \mathrm{~m} / \mathrm{s}$ \\
\hline 4 & $\begin{array}{l}\text { Typical natural smoke vent, } 0.4 \mathrm{~m} \text { (height) } \times 0.4 \mathrm{~m} \text { (length) }\left(\text { two sided) }=0.4 \times 20 \times 2=16 \mathrm{~m}^{2}, \text { no }\right. \\
\text { wind }\end{array}$ \\
\hline
\end{tabular}

Table 2 Beaufort wind scale.

\begin{tabular}{lllll}
\hline Beaufort wind scale & Type of wind & General description & Speed $(\mathrm{m} / \mathrm{s})$ & Knots per second $(\mathrm{kt} / \mathrm{s})$ \\
\hline 0 & No wind & Smoke rises vertically & Less than 0.3 & Less than 1 \\
\hline 1 & Light air & $\begin{array}{l}\text { The smoke indicates the wind direction, though the } \\
\text { wind is not strong enough the turn the wind indicator }\end{array}$ & $0.3 \sim 1.5$ & $1 \sim 3$ \\
\hline 2 & Slight breeze & $\begin{array}{l}\text { The wind is strong enough to be felt and is capable of } \\
\text { shaking tree leaves and the wind indicator }\end{array}$ & $1.6 \sim 3.3$ & $4 \sim 7$ \\
\hline 3 & Gentle breeze & $\begin{array}{l}\text { Tree leaves and branches shake continuously, while } \\
\text { flags flutter }\end{array}$ & $3.4 \sim 5.4$ & $8 \sim 12$ \\
\hline 4 & Moderate breeze & $\begin{array}{l}\text { Dust and paper shreds are blown up by the wind and } \\
\text { tree branches shake }\end{array}$ & $5.5 \sim 7.9$ & $13 \sim 16$ \\
\hline 5 & Fresh breeze & Small trees with leaves start shaking & $8.0 \sim 10.7$ & $17 \sim 21$ \\
\hline 6 & Strong breeze & $\begin{array}{l}\text { Tree branches start shaking, cable lines produce } \\
\text { whirring noises, and umbrellas cannot be opened }\end{array}$ & $10.8 \sim 13.8$ & $22 \sim 27$ \\
\hline 7 & Near gale & $\begin{array}{l}\text { The entire tree starts shaking and walking against the } \\
\text { wind proves difficult }\end{array}$ & $13.9 \sim 17.1$ & $28 \sim 33$ \\
\hline
\end{tabular}




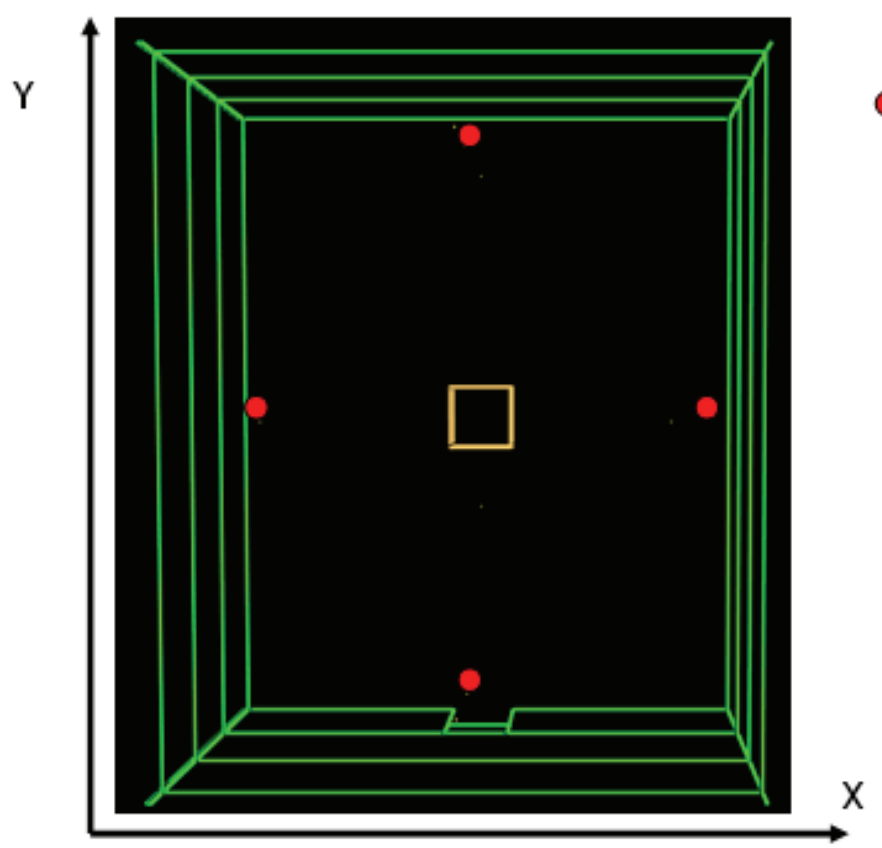

Fig. 5 Schematic configuration positions of testing points.

Table 3 FDS testing points settings.

\begin{tabular}{ll}
\hline Testing point serial number & FDS testing point settings \\
\hline TC5 & \&THCP XYZ=8,2,3,QUANTITY='soot density'/no.5 \\
TC6 & \&THCP XYZ=8,2,6,QUANTITY='soot density'/no.6 \\
TC7 & \&THCP XYZ=8,2,9,QUANTITY='soot density'/no.7 \\
TC8 & \&THCP XYZ=8,2,12,QUANTITY='soot density'/no.8 \\
TC9 & \&THCP XYZ=8,18,3,QUANTITY='soot density'/no.9 \\
TC10 & \&THCP XYZ=8,18,9,QUANTITY='soot density'/no.11 \\
TC11 & \&THCP XYZ=8,18,12,QUANTITY='soot density'/no.12 \\
TC12 & \&THCP XYZ=2,10,3,QUANTITY='soot density'/no.13 \\
TC13 & \&THCP XYZ=2,10,6,QUANTITY='soot density'/no.14 \\
TC14 & \&THCP XYZ=2,10,9,QUANTITY='soot density'/no.15 \\
TC15 & \&THCP XYZ=14,10,3,QUANTITY='soot density'/no.16 \\
TC16 & \&THCP XYZ=14,10,6,QUANTITY='soot density'/no.17 \\
TC17 & \&THCP XYZ=14,10,9,QUANTITY='soot density'/no.18 \\
TC18 & \&THCP XYZ=8,2,1.8,QUANTITY='soot density'/no.19 \\
TC19 & \&THCP XYZ=8,18,1.8,QUANTITY='soot density'/no.20 \\
TC20 & \&THCP XYZ=2,10,1.8,QUANTITY='soot density'/no.21 \\
TC21 & \&THCP XYZ=14,10,1.8,QUANTITY='soot density'/no.22 \\
TC22 &
\end{tabular}

effect on the natural smoke management system. Movement in air flow can guide the exhaustion of smoke through the natural smoke management design [14].

According to Scenario 1, Fig. 7 shows the vertical slice of the smoke flow at the 200th second and the
Positions of testing points soot density distribution at the upper half of the factory, showing that large amounts of smoke flow out from the design system.

Scenario 2 with a wind speed of $2 \mathrm{~m} / \mathrm{s}$ (wind direction $\mathrm{X}$ - towards $\mathrm{X}+$ ) illustrates the vertical smoke flow at the 200th second (Fig. 9), showing that the smoke 


\section{Numerical Analysis of Natural Smoke Ventilation Design System under External Wind Effect in Factory Compartment}

flowing out of the factory through the natural smoke management design system is affected by the external air flow, resulting in an unbalanced phenomenon.

Scenario 3 with a wind speed of $8 \mathrm{~m} / \mathrm{s}$ (wind direction of $\mathrm{X}$ - towards $\mathrm{X}+$ ) shows that the smoke flow is similar to that of Scenario 2. Fig. 11 shows the smoke flow horizontal slice at the 200th second at a 3-m height.

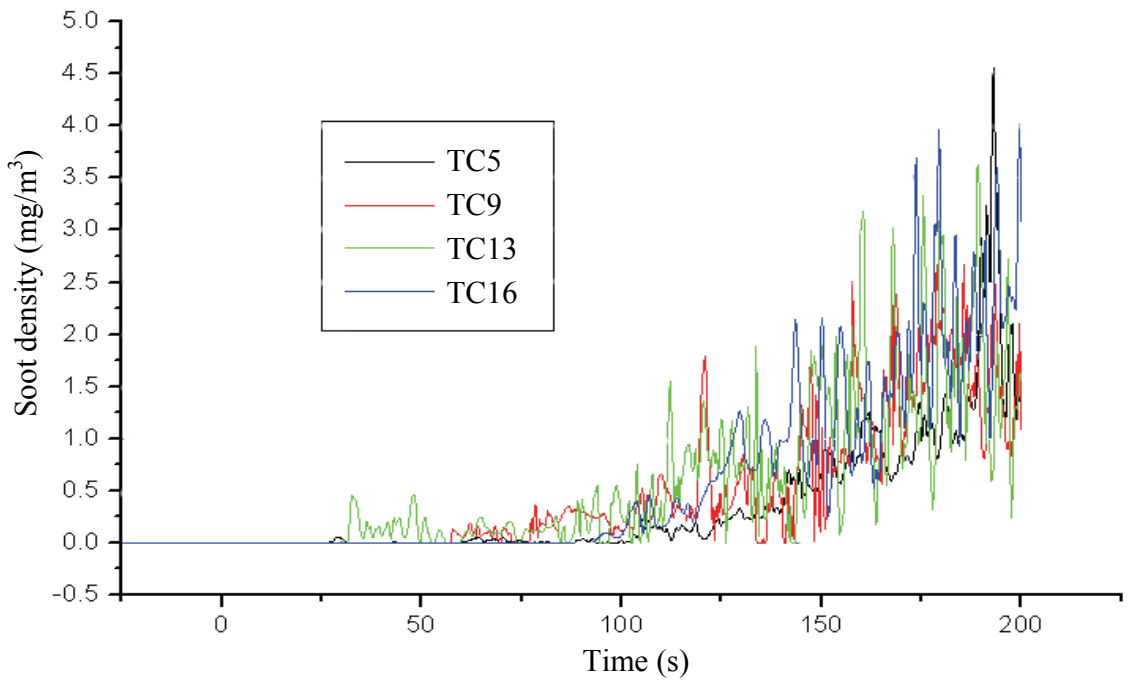

Fig. 6 Soot density variation with time at Scenario 1.

\subsection{Typical Natural Smoke Vent}

Fig. 12 show the soot densities of typical natural smoke vent under windy and no-wind conditions, respectively. Soot density under wind scenario is far higher than that under no-wind condition at 3-m height. In other words, under a typical natural smoke vent scenario, air flow leads to greater accumulation of smoke within the factory.

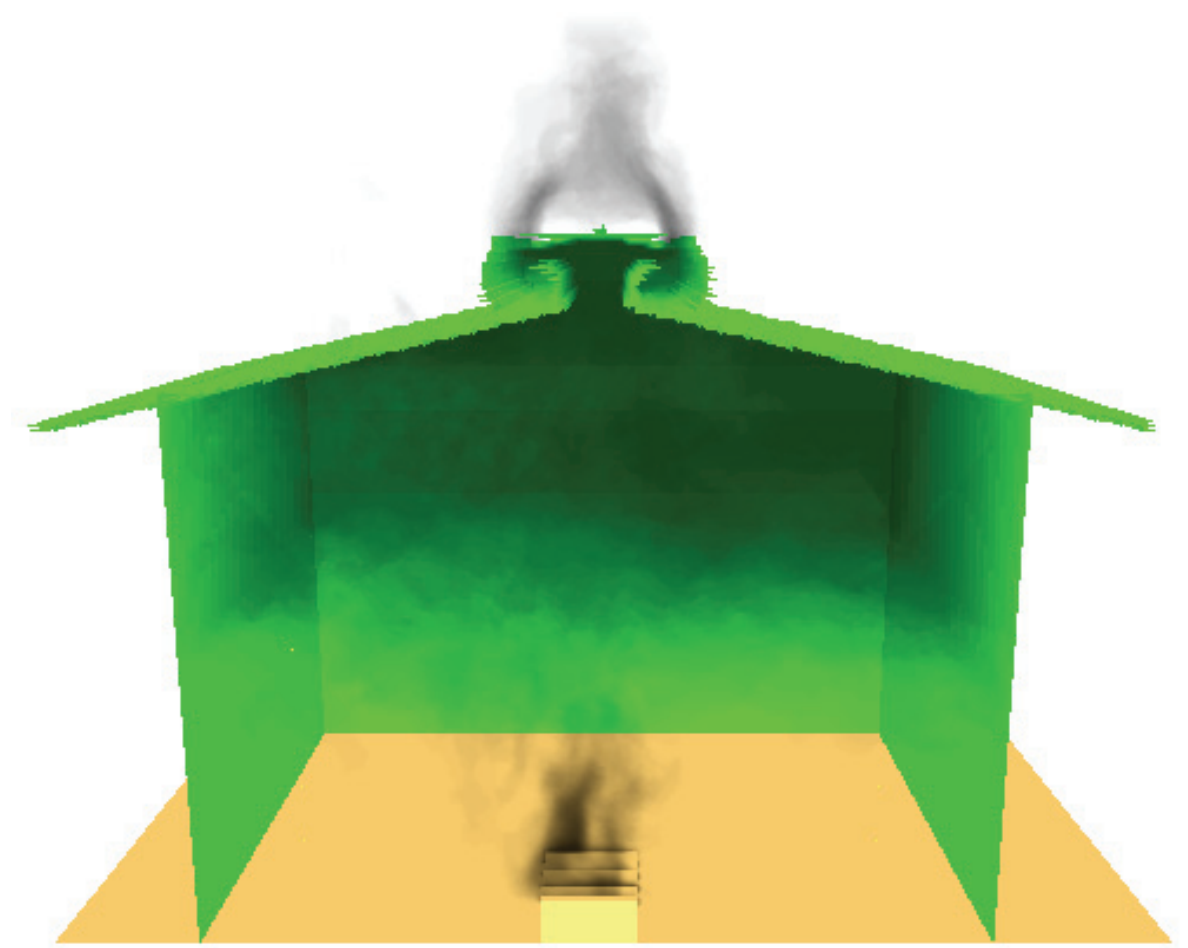

Fig. 7 Smoke flow accumulation at the 200th second at Scenario 1. 


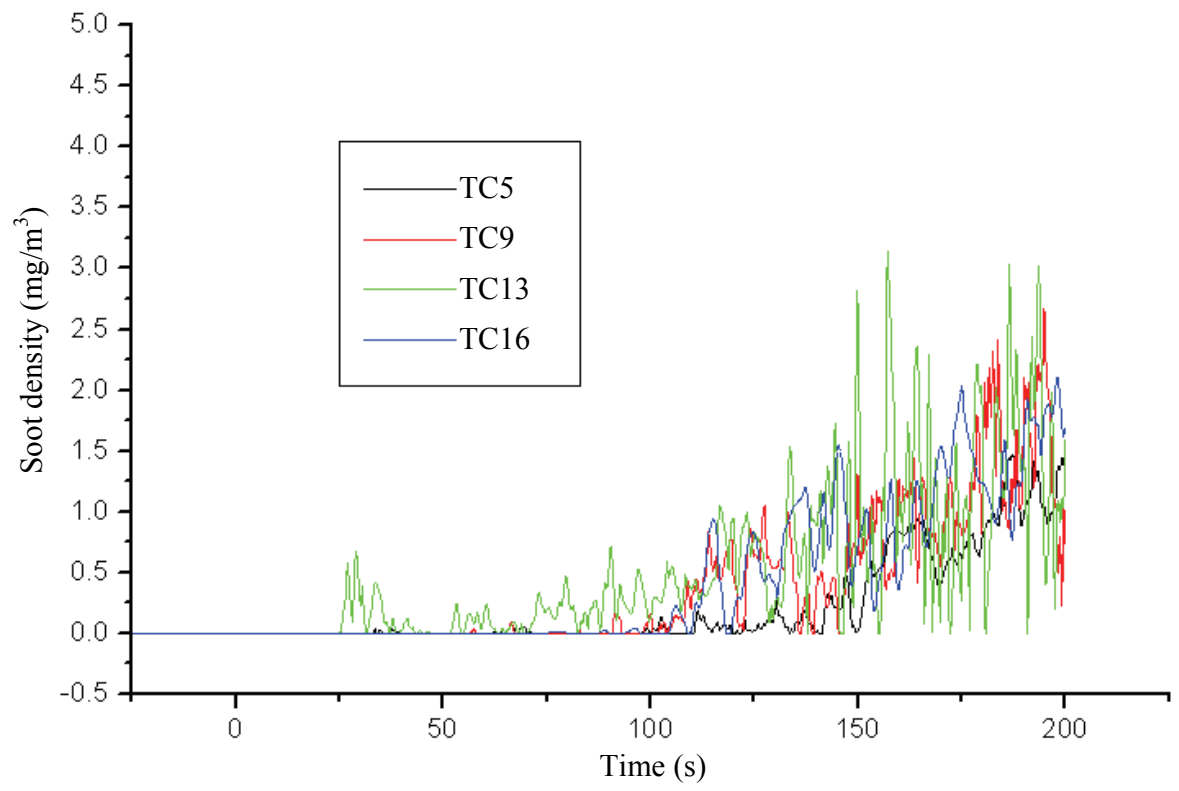

Fig. 8 Soot density variation with time at Scenario 2.

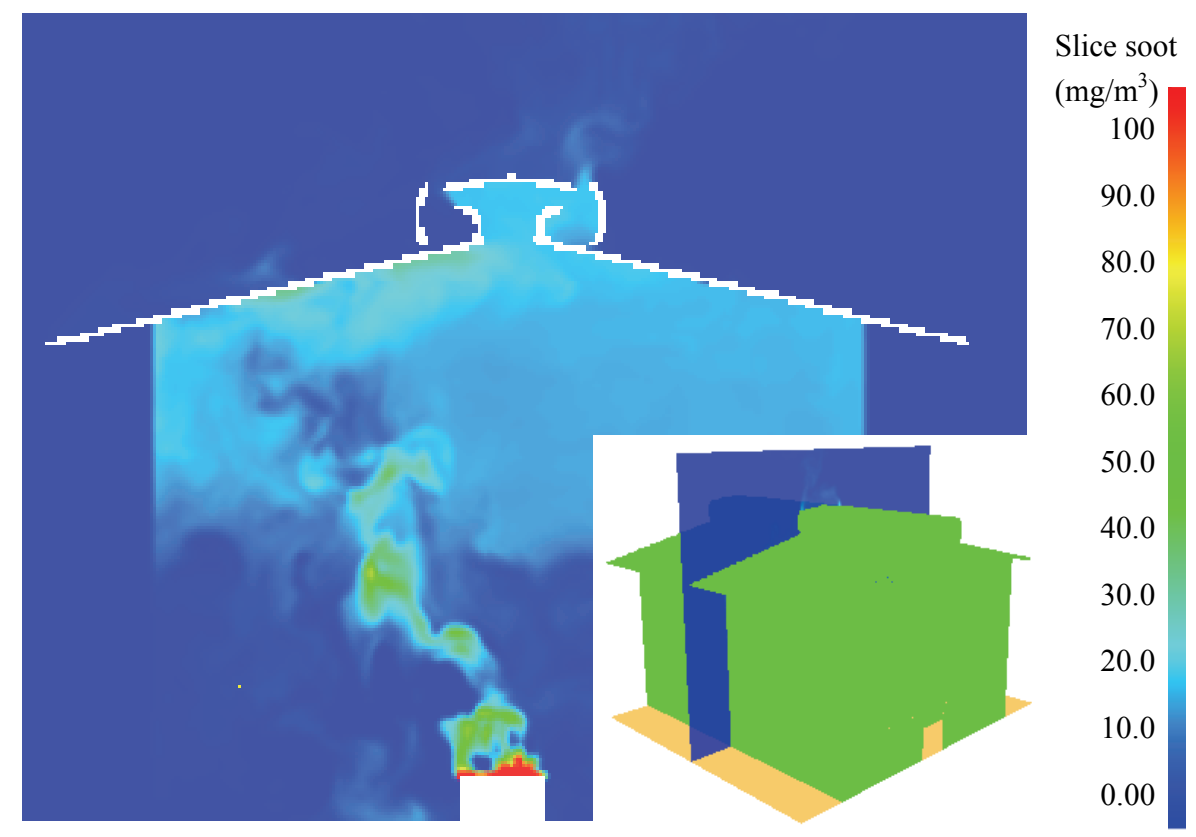

Fig. 9 Smoke flow vertical slice at the 200th second at Scenario 2.

A comparison of Figs. 6 and 9 shows that the natural smoke ventilation design system shown in Fig. 6 has a soot density growth trend lower than that of the soot density under a typical natural smoke vent. In other words, the natural smoke ventilation design system is more effective than typical natural smoke vent in no-wind conditions. A comparison of Figs. 8 and 10 shows that, under a windy condition, the natural smoke ventilation design system is more effective than typical natural smoke vent.

\section{Conclusions and Suggestions}

This study conducted a natural smoke ventilation design system simulation and compared its efficiency with typical natural exhaust vents under calm and windy conditions. The following conclusions were, 


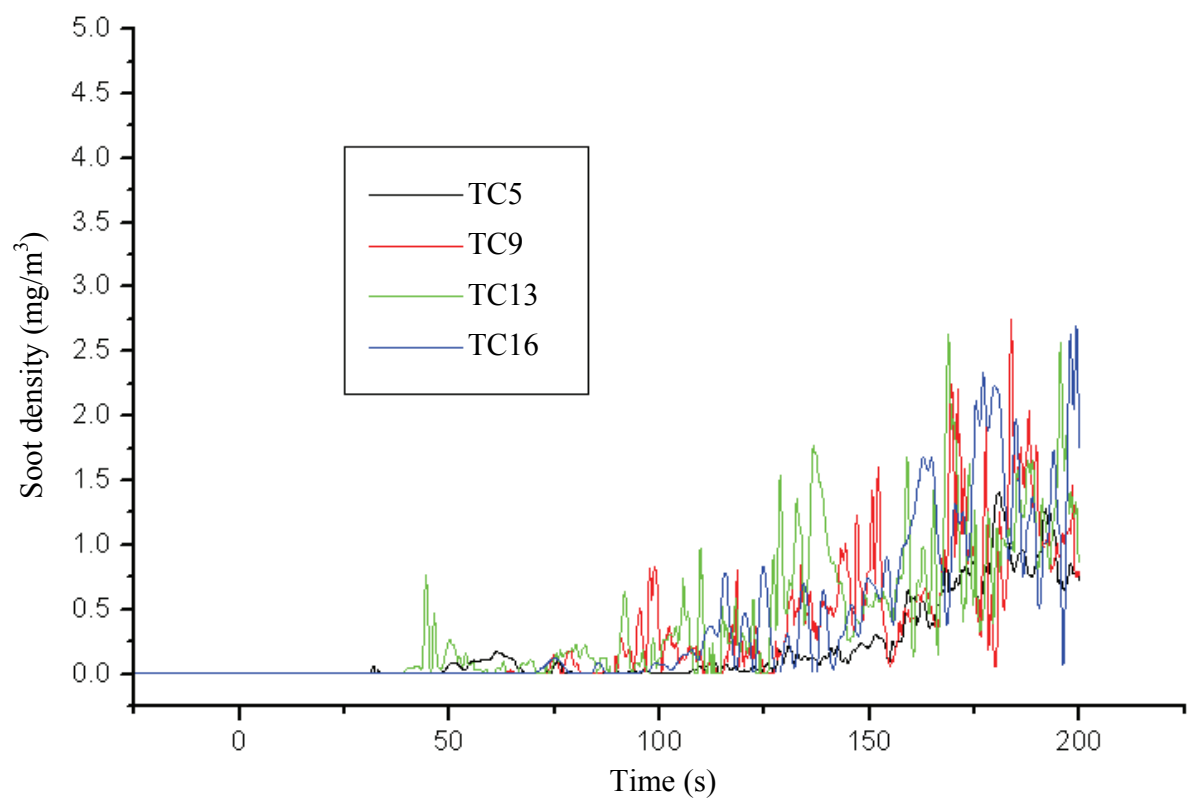

Fig. 10 Soot density variation with time at Scenario 3.

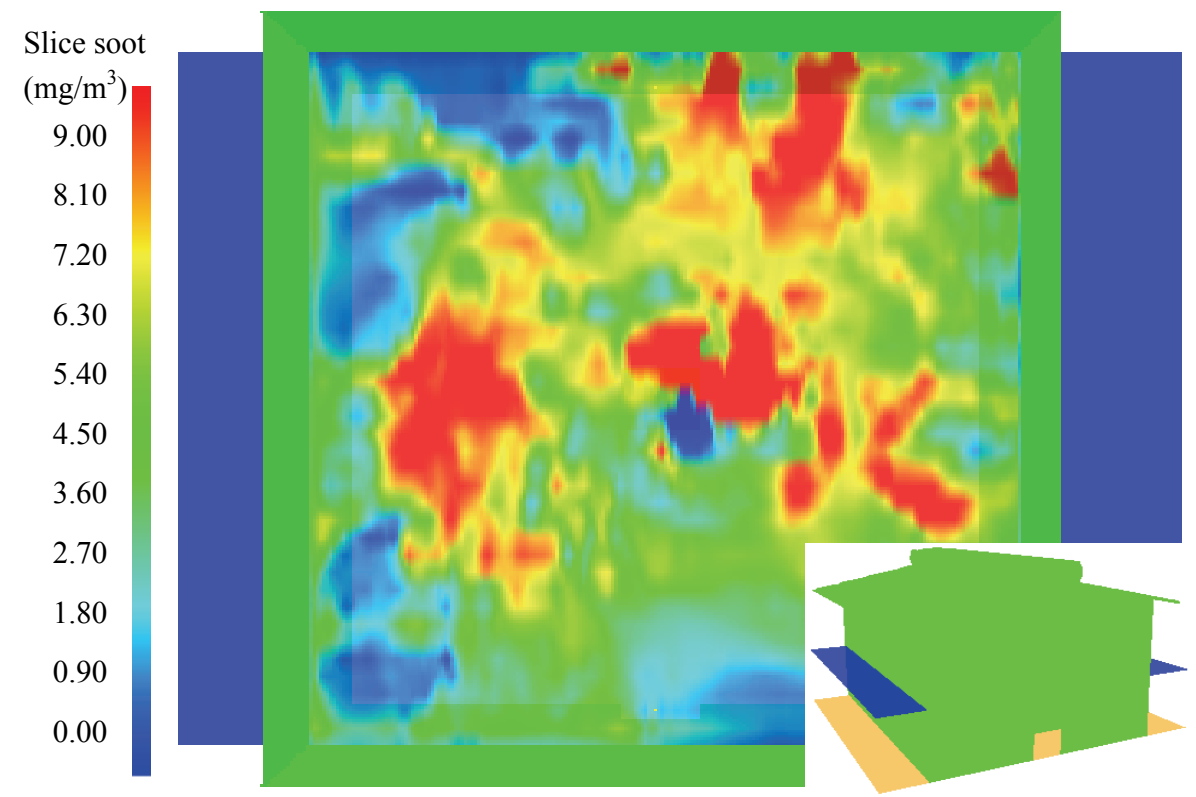

Fig. 11 Smoke flow horizontal slice at the 200th second at a 3-m height at Scenario 3.

therefore, obtained:

- The natural smoke ventilation design system was situated at the top of the factory with a $2-\mathrm{MW}$ fire source in order for the smoke flow to effectively converge. Assuming an identical opening area, the exhaust efficiency is higher than that of exhaust vents;

- The simulation discovered that the exhaust efficiency of a natural smoke ventilation design system under a 2-MW fire source scenario is higher than that of an exhaust vent with an opening area 2-fold larger;

- External air flow does not affect the smoke exhaust of natural smoke ventilation design system systems but, instead, enhances their exhaustion efficiency;

- Natural exhaust vents are easily affected by external wind, which results in difficulties in exhausting 


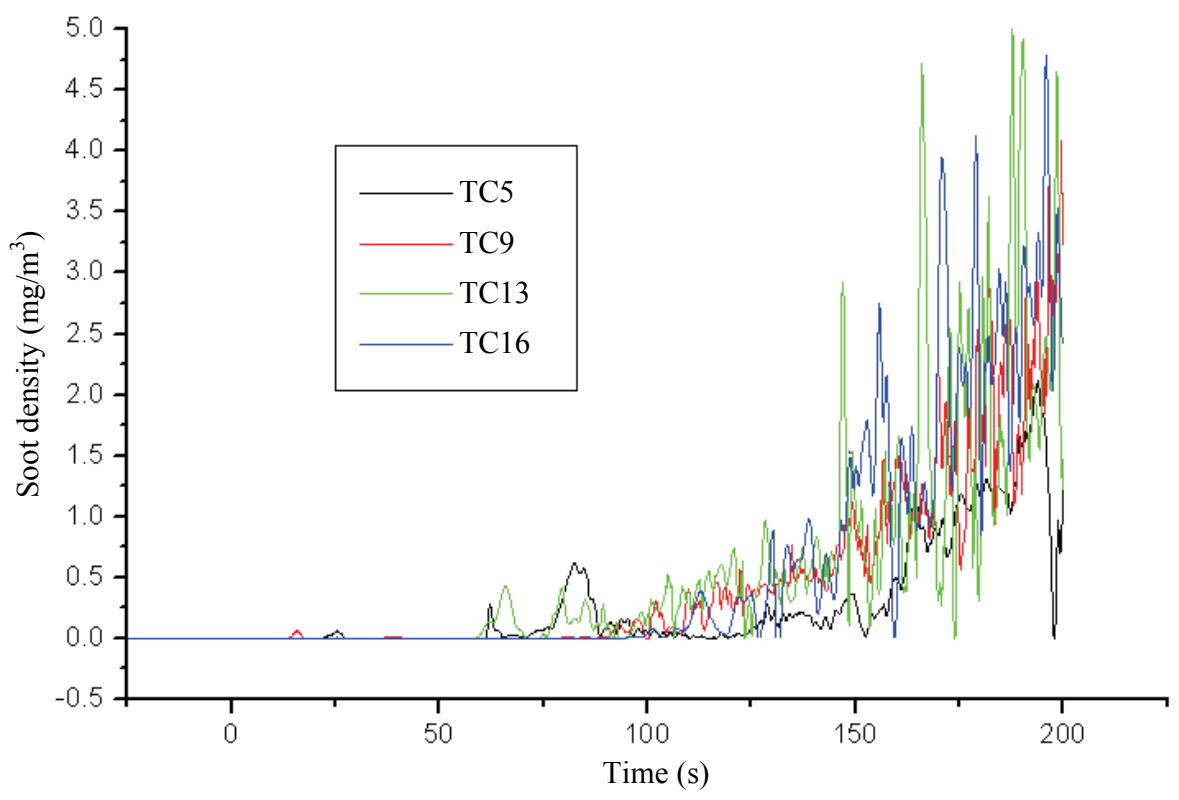

Fig. 12 Soot density variation with time at Scenario 4 .

the smoke. Instead, the vents become inlets for external wind resulting in the spread of smoke inside the factory.

\section{Acknowledgments}

The authors are indebted to Ministry of Science and Technology (MOST-101-2625-M-261-001-MY3) and Da-Zhu National Engineering Company of Taiwan, Republic of China, for financial support.

\section{References}

[1] NFPA (National Fire Protection Association). 2010. NFPA 92A: Recommended Practice for Smoke-Control Systems. Quincy: NFPA.

[2] Chow, W. K., and Li, J. 2004. "Wind Effects on Performance of Static Smoke Exhaust Systems: Horizontal Ceiling Vents." In Proceedings of ASHRAE 2004 Annual Meeting, 1-10.

[3] Porch, M., and Trebukov, S. 2000. "Wind Effects on Smoke Motion in Buildings." Fire Safety Journal 35 (3): 257-73.

[4] Yuan, J., and Glicksman, L. R. 2007. "Transitions between the Multiple Steady States in a Natural Ventilation System with Combined Buoyancy and Wind Driven Flows." Building and Environment 42 (10): 3500-16.

[5] NFPA (National Fire Protection Association). 2012.
NFPA 92B: Guide for Smoke Management System in Malls, Atria and Large Areas. Quincy: NFPA.

[6] Linden, P. F. 1999. "The Fluid Mechanics of Natural Ventilation." Annual Review of Fluid Mechanics 31: 201-38.

[7] Li, Y. G., and Delsante, A. 2001. "Natural Ventilation Induced by Combined Wind and Thermal Forces." Building and Environment 36 (1): 59-71.

[8] Xie, D., and Zhang, W. L. 2011. "The Effect of Natural Wind to the Atrium Building Smoke Migration." Procedia Engineering 11: 560-5.

[9] Marchant, E. W. 1984. "Effect of Wind on Smoke Movement and Smoke Control Systems." Fire Safety Journal 7: 55-63.

[10] NIST (National Institute of Standards and Technology). 2012. Fire Dynamics Simulator (Version 5.53) User's Guide, NISTIR 6784. Gaithersburg: NIST.

[11] Hansell, G. O., and Morgan, H. P. 1990. "Smoke Control in Atrium Buildings Using Depressurisation, Part 1: Design Principles." Fire Science Technology 10 (1): 11-26.

[12] Kandola, B. S. 1986. "The Effects of Simulated Fire Pressure and Outside Wind on the Internal Pressure Distribution in a Five-Story Model Building.” Fire Safety Journal 10: 211-27.

[13] Kline, S. J., and Mcclintock, F. 1982. "Describing Uncertainties in Single-Sample Experiments." Mechanical Engineering 104: 250-60.

[14] Meroney, N. R. 2011. "Wind Effects on Atria Fires." Journal of Wind Engineering and Industrial Aerodynamics 99: 443-7. 